\title{
Small-scale farming and gender-friendly agricultural technologies: the interplay between gender, labor, caste, policy and practice
}

\begin{abstract}
In this paper, I examine the interplay between gender, labor, and technology within an emerging, alternative, rice-growing technique called the System of Rice Intensification (SRI) to understand how in situations of agrarian transition, technology affect and influence social dynamics. The technology under consideration in this paper is a small, labor-saving device, called the weeder, seemingly suitable for smallholder farmers, and often projected as a gender-friendly device. The purpose of this paper is two-fold. First, to discuss and demonstrate how intersections of gender, caste and class issues even within agro ecological farming practices can result in experiences that can be highly differentiated. Second, to question and argue against the naturalization and/or apparent lack of problematization of production of such social difference and material outcomes. The paper draws theoretical insights from feminist political ecology (FPE) and feminist technology studies (FTS) and is based on an extended ethnographic fieldwork in Bihar, India.
\end{abstract}

Keywords: smallholder farmers, SRI, gender, labor, technology, agricultural intensification, India

\section{Contact details:}

Dr. Regina Hansda

Research Fellow, Centre for Rural Economy (CRE)

Agriculture Building

Newcastle University

Newcastle-upon-Tyne,

NE6 5EA

Email: Regina.Hansda@newcastle.ac.uk 


\section{Introduction}

In the recent debates around food (in)security, there is a push by donor and government agencies for encouraging smallholder agriculture (HLPE, 2013; IFAD, 2013). Since land is a shrinking resource, wide consensus exists that 'agricultural intensification' is the way forward for increasing future farm productivity and in turn food security-irrespective of the size, scale and methods of farming (FAO, 2011). The premise of this paper is, whatever the model of agricultural development - whether a single, standardized approach or a combination of practices (agro-ecological or mixed method), agricultural intensification necessitates the use of agricultural technologies in varied forms and degrees (Boserup, 1991). And in the case of smallholder agriculture, it is most likely to be mediated by simple, small, technological interventions. In the geographies of agricultural technologies literature, technology in a broad sense refers to any one or all of the following things together. These pertain to tools and equipment, practices and techniques, and knowledge and skills arising out of applied sciences and/or traditional knowledge systems. But the popular categorizations, which are based on different permutation and combination of each of these are on new seed technologies, agronomic practices, and farm mechanization ${ }^{1}$ (Agarwal, 1984; Paris and Pingali, 1994; Singh et al., 2006).In this paper, therefore my attention is more on small-scale technologies, of relevance for smallholder farmers, that fall largely within the realm of tools and equipment.

The development, agricultural economics and agricultural engineering literature has discussed to some extent the need and experiences of smallholder farmers on this particular technological category (Biswanger and Pingali, 1988; Singh, 1997; Biggs, Justice and Lewis, 2011), but not so much on the gendered experiences (Kolli and Bantilan, 1997). During the GR period and beyond in India, it was men who invariably played a greater role in access and use of technologies. In the tools and equipment category of technology, the engagements of women particularly remained rather limited; and pertained mostly to small hand-held tools like hoe, sickle, and spade amongst others. Couple of reasons has been ascribed to this gendered patterned of access and use of technologies. Notable amongst those are the gender division of farm labor that limited the responsibilities of heavy and laborious aspects of farm work to men. Second, agricultural farm tools that fall within the rubric of heavy machineries generally come with a high price tag requiring specific knowledge and skill-sets to operate and maintain, which invariably men were 
perceived to be better suited for. Third, cultural norms and social expectations determined that men use and operate agricultural tools and equipment towards farm mechanization, as it is more in sync with their physical abilities as compared to women. Feminist scholars have critiqued each of those above positions suggesting how tasks 'traditionally' associated with men (e.g. land preparation, irrigation) have predominantly received attention for technological intervention as opposed to those done by women farmers (e.g. transplantation, weeding, harvesting) and how each of the activities performed by women are equally tedious and laborious (Mencher and Saradamoni, 1988; Doss, 2001; Lohan and Faulkner, 2004). Similarly, the suitability question about men as being better suited to deal with, and/or operate machines rests on social constructions of gender as to what is 'appropriate' for each of the genders to perform based on particular notions of femininity and masculinity, rather than their actual abilities (Liepens, 2000; Brandth, 2006).

In terms of contributions, I argue that in the case of small-scale technologies in the context small-scale farming similar experiences of gendered labor displacement as was the case during the GR is not tenable. The reason is because the nature of the technology under consideration is quite different, unlike what much of the agricultural technology studies are largely based on (e.g. large machineries like tractors, combine harvesters, motor pumps, and tube-wells). In most of the above technologies there is the issue of heaviness, mechanicalness, expensiveness, newness and knowledge intensiveness amongst others. In the case of simple, small, cost-effective technologies, many of these aspects, do not necessarily apply; and if it does, it is at a very minor level. By using the case study of the weeder technology within system of rice intensification (SRI) in Bihar, this paper demonstrates how despite its suitability for women farm workers in terms of design and cost, access and use can still be an issue. So, some of the questions this paper raises are how and why does women benefit/not benefit from such interventions around small-scale technology, what role does caste, class, social norms and perceptions around gender or for that matter inadequate policy attention and interventions play in shaping social outcomes around technology. I demonstrate that the problem is not just the social norms that can limit technology use, but also how policy and practice miss gender transformative opportunities.

The paper is organized as follows, it begins by reviewing the literature on agricultural technologies and the theoretical foundations on which many of the technological 
interventions has been based so far, and what it has meant for gendered outcomes. The paper then discusses the research methodology and the social context within which the research is based. Following this, it discusses the specific technology under consideration — the weeder, in terms of its purpose, design, costs, and the broader narratives surrounding this technology. It further discusses the relationship between social norms, policy, practice and the influence it has on shaping technology-related outcomes.

\section{Gender and agricultural technologies - a conceptual framework}

There are two broad sets of discourse, which emerge distinctly around technology and gender. One, which argues in favor of increasing farm efficiency and productivity through the use of labor-saving devices (Gulati et al., 2014; Murali and Balakrishnan, 2012). The other, as a measure to reduce women's drudgery onfarms, who are burdened disproportionately as compared to men (Kishtwaria and Rana, 2012; Mehta et al., 2012).Most of the agricultural technologies literature in India can be classified into three broad categories; namely, a) farm mechanization; b) those relating to modernized agriculture related inputs (seed technologies, chemical inputs); and c) associated agronomic practices. In terms of gendered labor implications, the different sets of scholarships in each of these areas highlight different forms of subjective experiences. These range from labor displacement and redundancy from farm work to landlessness and/or casualization of farm workers. The farm mechanization literature in particular demonstrate how the use of devices such as tractors, combine harvesters, threshers and rice mills contributed to both increase, as well as decrease in labor demand for different categories of farmers. The loss or gain in employment opportunities, (in the case of households extra or less demands on labor) for each of the genders depended on the traditional gender division of labor. For instance, male agricultural laborers lost out on employment with the increased deployment of tractors and threshers (Hart, 1991). Women laborers on the contrary lost out because of the use of combine harvester (Malaysia, Hart, 1991), rice-milling facilities (South Asia, Hariss-White, 2005), and use of new seed technologies and chemical inputs (Billings and Singh, 1970; Agarwal, 1983) — essentially all those tasks in which women laborers played a significant role. From the nature of the technologies used what become evident is that these agricultural technologies were usually large and expensive, that catered to the needs of medium and large farmers. Smallholder farmers, were rarely the focus of technology development, less so the women farmers. A review of literature of the last decade in the Indian context suggests that there are some 50 odd hand tools/manually-operated 
agricultural implements that have been developed by various research organizations that small farmers can potentially use with relatively less recurring costs (Singh et al., 2006; Deshmukh and Tiwari, 2011; Mehta et al., 2012; Biggs, 2015). In order to address some of these concerns, development practitioners, agrarian researchers and activists have argued for the development and promotion of gender-friendly technologies that can reduce some of the drudgery of women farmers and laborers (Doss, 2001; Paris and Chi, 2005; Carr and Hartl, 2010). The 'closing the gender gap' literature too reiterate how lack of attention to women's need in technology design and access forecloses the possibility of enhanced farm productivity, especially for crops in which women play a predominant role.

To understand the reasons why women farmers have consistently remained outside the frame of technological development, I draw upon feminist technology studies (FTS) and feminist political ecology (FPE), which together enable a nuanced understanding of the relationships between gender, agriculture, labor and technology. It is important to point out that most of the gender, labor and technology analysis from feminist perspective have emerged outside the agrarian literature. These include studies on reproductive technologies, household technologies, education and information technology amongst others (Cockburn and Omrrod, 1993; Faulkner, 2000; Boyer and England 2008).The agricultural literature on the embodied gendered aspects of work, body and technology are mainly from the global North and highlight useful issues and perspectives, but these are inadequate to help explain the complex experiences surrounding caste practices as encountered in the South Asian context (Liepens,2000; Brandth, 1995, 2006). The literature on gender and caste relations in the Indian rural context though are helpful in elucidating the dynamics of caste practices, but these analyses do not substantively provide insights into the embodied and gendered aspects of labor vis-à-vis farming implements and tools (Omvedt, 1979; Mencher and Saradamoni, 1988). I therefore, draw from both these bodies of work to make sense of the empirical findings in the context of Bihar.

There is a fair amount of literature on FTS to support the contention that technology introduction apart from being labor-saving can have other associated impacts in general, which can be complex and contradictory (Brandth, 1995; 2006; Cockburn et al., 1992; Lohan and Faulkner, 2004). Such an understanding is possible especially when the standard political ecology questions are asked as to who benefits and loses from any kind of technological introduction in the social environment in which it is introduced. There are three broad strands of literature within FTS discourse which are helpful in elucidating the 
reasons behind the entrenched practices of gendered exclusions; and these are from: a) the essentialist approach, b) the anti-essentialist approach, and c) poststructuralist lens. The essentialist approach for instance follows a technological deterministic argument and is based on the idea that technology follows a predictable path ("inevitability thesis") beyond any social, cultural, and political influence (Chandler, 1995). According to this school of thought, gender does not determine how any technology spatio-temporarily evolves over a period in any given context. Once the technology has been introduced, the concerned societies organize themselves in a way to reject or support, develop and further improve the technology. Feminist theorists especially of constructivist persuasions have critiqued the inherent gender blindness in such a line of thinking. According to them, the evident gender and technological gap is essentially because the designers and users of most technologies are essentially of the same gender. The point these scholars raise is how technology itself is gendered and masculine in nature considering it is largely men who traditionally designed technologies, keeping the needs and interests of men, based on their locations within various structures of power (Cockburn et al., 1992; Lohan and Faulkner, 2004). In addition, how such a line of thinking and every day operation inherently invisibilizes the gendered dimensions of technological practice in terms of design, delivery and outcomes. Other problematic outcome of such an approach is that it creates conditions for reproduction of gender stereotypes about capabilities, work and employability.

The anti-essentialists on the other hand view technology as gender-neutral by intention and design, and refute the idea that technology itself is about control and domination by men over women's labor and work space (Grint and Gill 1995; Grint and Woolgar, 1995). Anti-essentialists call for a broad-based, long term strategy that can encourage redesigning of technologies and widening access and opportunities to previously excluded social categories (read as 'gender-aware', 'gender-sensitive'). Critics of anti-essentialism argue that gendered values and politics are inscribed in the technology in the very process of its construction, deployment, and consumption, and therefore until and unless the patriarchal origins of technology are challenged, with greater involvement of women in technological domain and space, not much can change. Judy Wacjman one of the key critics of antiessentialism writes "...technology may have been seen as socially shaped, but shaped by men to the exclusion of women..." (Wajcman, 2010, pp.147)

The third, a relatively recent strand, which I draw upon substantially from, is the poststructuralist framework that challenges both the technological deterministic approach 
of the essentialists, and the presumed neutrality of the anti-essentialists. According to this framework, what is vital is to deconstruct and understand the social and political meanings that specific technologies assume through discursive acts and practices; and how various structures, symbols and identities are constructed and understood through these very processes (Butler, 1990; Bordo, 1993; Faulkner, 2001; Saugeres, 2002; Brandth, 2006). For analysis of my empirical findings, I have also drawn insights from feminist political ecology (FPE) scholarship to demonstrate the inter-connectedness of the economic, ecological and cultural aspects of natural resource-based livelihoods, to suggest that processes of change can affect women's lives quite differently from that of men - especially for the poorest amongst them (Rochleleau, 1996; Elmhirst and Resurreccion, 2008).

\section{The research context and methodology}

The major source of data used in this paper is based on more than a year of ethnographic doctoral fieldwork from July 2012-June 2013 in three villages in the Bodhgaya block of Gaya district in Bihar in Eastern India. The choice of the district within the State and the block and village(s)was finalized using stratified purposive sampling. Gaya district, located in the South of the Ganges, was identified as an appropriate site for conducting this research for the following reasons. One, it was the first district in Bihar to adopt and practice SRI since 2007-2008 under a World Bank-supported rural livelihoods program called 'Jeevika'; and two, Gaya is a drought-prone district, having the highest concentration of dalits $^{2}$ (approx. 30\%) in the State, therefore, quite relevant from a food security perspective. For the purpose of my research, I examined three villages; Shekhwara, Pathra and Satgharwa in Shekhwara Panchayat, all lying within a radius of two kilometers from each other. These villages, together, more than individually can be considered as representative village(s) in the South Bihar region-given their similarity in terms of agrarian structure, caste composition and natural resource endowments. The selected villages enabled me to capture the impacts of this relatively different rice growing technique on gender and labor relations across different categories of farmers: men and women farmers and farm workers mediated by their caste, class and age. The villages under study exhibit varying degrees of caste composition from relatively more homogenous in the case of Satgharwa (yadavs) to mixed groups (Shekhwara and Pathra, but each having significant mahadalit ${ }^{3}$ population). Land ownership pattern is more or less even with about 90 per cent of them as small and marginal farmers owning less than 2.0 ha of land and 
under different tenural systems. The semi-medium and medium farmers are few in numbers, own land between 5-10 acres, and are mostly from the kahar and yadav community constituting the 'middle castes', popularly known as the other backward castes (OBCs). These two broad categories constitute the local elites, having varying degree of social and political power mainly because of their landholdings size, access to resources, and influence in the local institutions. Most of the agricultural labor in all these villages comes from the mahadalit community. Migration for work is common in Gaya district as a whole (Deshingkar et al 2006), but not so much from Bodhgaya, given its international tourist destination status. During the off-peak agricultural season many men from the mahadalit community seek work as casual workers either on brick kilns, local construction sites or pull rickshaws in and around Bodhgaya, which is not the case for women.

For data collection I have used a combination of ethnographic research tools such as participant observation, in-depth semi-structured interviews, and focus group discussions (FGDs) with both women and men farmers and agricultural laborers. The details of the tools and sample size of each are as follows: Focus groups [(9), comprising 6-8 people (6 in Shekhwara, 2 in Pathra and 1 in Satgharwa)]; Key informant interviews[(15) - 7 farmers, 2 NGOs, 6 key government officials] and In depth semi-structured interviews [(27) - 75\% in Shekhwara village with small farmers and agricultural laborers, and the rest in the other two villages]. 


\section{The system of rice intensification (SRI) and the weeder technology}

SRI is an emerging, alternative, and regenerative method of rice cultivation that is claimed to remarkably enhance rice yield and productivity, with reduced use of inputs (Uphoff, 2003; Kassam et al., 2011). An aspect of the technique, which is problematic though, is the issue of excessive weed growth. This problem largely occurs because one of the core principles of SRI recommend limited use of water through alternate wetting and drying of fields-as opposed to the conventional practice of keeping the rice fields continuously flooded (Uphoff and Randriamiharisoa, 2002). It is this change in water management practice in SRI, radically different from the conventional method the main reason behind SRI's excessive weed growth (Adusumilli and Laxmi, 2011; Ghritlahre et al., 2012; Mitra et al., 2013). Weeding is a critical agricultural task within SRI, failure to do so can have a significant bearing on the yield, possibly nullifying some of its yield advantages (Satyanarayana et al., 2007; Mohanty and Mohanty, 2010; Mohapatra et al., 2012). The conventional weed management practice entails using any or all of these options: chemical method (through use of herbicides), non-chemical method (keeping rice fields in a continuously flooded conditions), and manual method (through hand weeding). SRI on the contrary recommends frequent weeding through the use of the "weeder" - the smallscale technology under consideration for this paper.

In terms of design and cost, the weeder is a metallic device about five to six feet in length, weighing between 6-8 kilograms, and costing about $f^{8-11^{4}}$. It has a narrow pointed pan on one end and spiked roller blades on the other. On applying pressure in a straight line, these blades roll, cut, and churn the mud; and alongside it destroys farm weeds as well. It can be reasonably argued that with its light weight and simple features, the weeder has markedly changed the way weeding is carried out in rice cultivation mainly in terms of posture, technique and strength. The popular narratives around the weeder therefore, pertain to its cost-effectiveness as well as its suitability for smallholder farmers. Even in SRI literature, much of the discussions center around the agronomics and ergonomics aspects of weeding practices and the weeder technology (Deshmukh and Tiwari, 2011; Kishtwaria and Rana, 2012). There is little conversations on the gender dimensions of the technology in SRI literature; and if they do, standard claims are asserted about the weeder's labor-reducing and efficiency-enhancing potential. For instance, B.C. Barah, the NABARD $^{5}$ Chair Professor at the Indian Agricultural Research Institute (IARI) while asserting the claims about equitable gender participation within SRI writes “...women 
laborers find the ergonomically manufactured weeders more user friendly..." (Barah, 2009, pp. 211). Another study in Andhra Pradesh found that mechanical weeders apart from reducing physical discomfort in weeding work, reduced women's labor time by up to $76 \%$ (Mrunalini and Ganesh, 2008). The engagement with questions of gender and the laboring body' that actually works on and with the tool are few. The few that does emphasize the benefits this technology brings to women farmers are in terms of reducing their drudgery(weeding from a bent to an upright posture) and reduced musculo-skeletal fatigue associated with conventional weeding method (Kishtwaria and Rana, 2012; Sabarmatee, 2014). These are all fair claims to some extent and might be the case in some states. However, evidence from my research site in Gaya suggests a more complex picture, and the idea of this paper is to nuance the existing discussions. Based on my empirical findings, I argue that the introduction of the weeders is leading to a shift in gender and labour dynamics whereby men are increasingly being engaged and preferred for a role which was traditionally seen as 'feminine', and performed by women only. Women are either not expected to, or given the opportunities by the employers to operate the weeder. Why is that the case, I explore and discuss some of these aspects in the following sections of the paper.

\section{The weeder technology and reorientation of spaces of work}

Post the introduction of the weeder in the studied area, there are different ways in which work pattern and employment opportunities around weeding are being re-oriented, both from within and outside the household. In the conventional method, it is only women who do weeding irrespective of the size of landholdings. The most striking feature of this shift in labor is that in the case of marginal and small farmers, weeding work is increasingly being performed by men from within the household, whose contribution does come as a respite for women in such households. But in the case of semi-medium, medium and large farmers (SmML), weeding work is mostly outsourced to hired (men) waged laborers. Even small farmer households to some extent in the research site are also able to outsource the weeding work to hired wage laborers. This is possible because wages in the research site are still largely paid in kind (rice); and the enhanced rice production possibility under SRI technique has enabled many small farmers to use their additional produce towards payment for hired wage laborers. So in some sense, for the men of the household, there is always an option of outsourcing the task, which may not necessarily be the case if the said work were to directly shift from women of the household to hired waged laborers ${ }^{6}$. The key 
point to note here is shift of weeding work in this case tends to bypass women agricultural laborers in favor of men from the same laboring caste and class.

Weeding as an agricultural task is critical within SRI, therefore, considerable attention is paid on ensuring that it is carried out properly. But the focus of most SRI practicing farmers (employers) in the research site is on ensuring timely availability of labor, instead of thinking about the gender of the worker. This uncritical approach I argue is restructuring workspaces. Lack of easy availability of the weeders (discussed in detail in later section) is creating conditions, where they are expected to work alone, which does not seem to be a great preposition for women farm workers. Traditionally, weeding in rice fields is done in a cohort, where groups of four to five women work together. Under this transitioning agrarian situation, it is usually one or two men from the laboring dalit community who do the weeding work using the weeder.

The traditional practice of weeding in a group has to be seen within the larger local context, where most farms in most villages are spread out across hundreds of hectares. For rural women, especially from marginalized communities, working outside their home can bring considerable risks (Rao and Rana, 1997), which could include unsolicited, predatory sexual behavior - a reality also for many working women in the South Asian context. In order to mitigate some of these risks, rural women usually tend to work in groups, as working together allow these women to collectively ward off any kind of verbal or physical abuse. Women from lower castes (constituting the bulk of the agricultural laboring community) are known to be far more vocal and unrestrained in their expression in situations of any kind of abuse and violations; and the strength to do so multiply, if they operate in a group, as opposed to working alone. Therefore, my contention is, such solitary weeding conditions within SRI is potentially non-conducive to the interests of women agricultural laborers leading to their further alienation from work and farming spaces. Also, it emerged from discussions that employer farmers are willing to pay hired waged men extra remuneration (a kilogram of more rice for a day's work than the standard practice) as compared to hired waged women; and this is mainly based on the notion that men can do better quality of weeding as compared to women in terms of area covered per day, and depth of soil churned which is good for overall crop productivity. Some women in the field site contest this perception, and others think that is the case. The net outcome is women's reduced participation in weeding-related work in the case of SRI. 


\section{The logic of 'bhaari kaam' and gender (in) appropriateness determining practices around technology}

As discussed in the earlier section, one possible explanation for preference of men over women laborers for weeding could be of getting a particular task done by those 'who can' do it, taking precedence over any other considerations. Although, the assumption as to 'who can' do-it-bit is problematic, and predicated on the notion that women cannot undertake tasks that require physical strength and labor. The 'heavy and light weight' logic is the predominant perception and is held both by men and women farmers in this case that impedes hiring of women agricultural laborers. The following quote is symptomatic of that dominant perception.

"...It is not that women cannot operate the weeder. But the fact it is slightly "bhaari kaam' (heavy work) that's why it is usually the men who operate the weeder in the village...”

- (A marginal male farmer who also engages in weeding work on other people's farms, Shekhwara, Bodhgaya)

Another woman farmer in the village, questioning this predominant notion around the weeder and gender explicitly states:

"...I can use the weeder quite comfortably, and I am the one who does most of the weeding work on the little SRI plot we have ... but I don't go out and work on other people's farms, as my husband does not approve of it..."

- (A marginal woman farmer who also work as agricultural laborer, Shekhwara, Bodhgaya)

The question then arises is, how does the same task when done on one's own farm space fail to qualify as a task that requires physical strength; whereas, when done on others' fields does? This particular example breaks the myth of weeding through the weeder as heavy work (bhaari kaam), which men can perform better in. My research also revealed that the issue is more complex than it appears, because had it been the case, then women would be restricted to perform tasks requiring physical strength even on their own farmland. What possibly could be the other reasons for such non-preference of women for hire by the employer; including the general non-approval by the husbands of willing women worker? Safety issue as discussed earlier is one. The other aspect which I think has largely to do with locally understood notions of masculinity and femininity around technology, which are discursively enacted by both women and men. 
There are ample feminist studies that demonstrate how gender ideologies can restrict or influence performance of any acts by men and women that appear contrary to the prescribed or ascribed gender roles (Bordo, 1993; Butler, 1990). The point is not whether men are more physically stronger than women, as it is possible to find ample examples which can demonstrate that women do engage and manage tasks that require physical strength and stamina; as well as men who do not-in different places, times and cultural contexts. The usual tendency within the hetero-normative framework then in such cases is to label one as 'less of a woman' or 'less of a man' for transcending/transgressing some of those gender boundaries (Saugeres, 2002). In her seminal work Gender Trouble, Judith Butler (1990) theorizes gender as a performative act wherein individuals tend to 'enact' their gender. One part of that enacting of gender identities is to demonstrate a lack of physical strength by women even when one is NOT weak. This is because since women are supposed to be physically weaker than men, they are seen to only be able to do those agricultural tasks which do not require physical strength. And even if they do, then it is either ignored or unacknowledged at the household level; and/or women themselves willfully undermine their own hard work, to act as a constant reminder of the existing biological differences. Some scholars argue that exhibiting physical strength especially in spaces outside the domestic arena amounts to women being de-sexualized and lacking sexual appeal, making one undesirable (Saugeres 2002, Faulkner 2001). The operation of the weeder on someone else's farm essentially amounts to demonstration of physical strength, and such women run the risk of being objectified as not being 'proper' women (Nussbaum, 1995). At this stage, it is pertinent to point out Cecile Jackson's paper on Gender, irrigation and environment (1998) where she reminds us that it would be misleading to assume that lack of women's engagement in tasks and roles demanding physical labor and technical knowledge is always a matter of social exclusion or social norms. Arguing for women's agency, she reiterates that just as “....men commonly seek to escape from manual labor when livelihoods permit - why should not women experience the same aversion to hard physical labor?...” (Jackson, 1998; pp.320). The point is well made, and in this context too, some women do tend to self-withdraw from weeding role. A small woman farmer once said to me:

“... My husband does the weeding on our farms, but if given a chance he would opt out of it, but I am glad he does the weeding, as its any day better than him doing 'adda' in the neighborhood ..." 
Not all men might do adda, instead explore opportunities which are more economically remunerating. However, what I want to emphasize here is the need to make a distinction between technological interventions that affect labor deployment from within the household, to labor employment from outside; as the implications in either of the cases are different. I contend that in situations where other livelihoods opportunities are limited (as is the case for women agricultural laborers in the research site), and if the choice is between expending physical labor and going hungry, ${ }^{7}$ the opportunity for former should not cease to exist (see also Gathorne-Hardy et al., 2016).

\section{Gender, caste, social norms and technology}

The issue of bodily practices and identity formations gets further complicated when gender intersects with caste (Nightingale, 2011). In such a scenario, articulations about 'social difference' become even more pronounced when gender-caste matrix is interlaced with questions of work, space and labor (Chakravarti, 1995; Heyer et al, 2000). Within the category of small-scale farmers, those who are able to practice SRI relatively more easily as compared to other communities, are the OBC farmers. OBCs constitute the dominant caste in the village, and men from this community do not consider it appropriate for their women folk to use the weeder, in other words engage in bhaari kaam. This line of thought was more prevalent in Shekhwara which had a mixed caste group.

“...Our women don't use the weeder, but you'll find some women from bhuinya community who do. They are strong women, unlike ours and are used to doing hard work. Moreover, it is okay in their community to do any kind of hard labor, which is not the case in our community (unke samaaj mein chalta hai, hamare mein nabi)..."

- (A smallholder male farmer from the OBC community, Shekhwara)

This particular quote suggest that the category of women is perceived differently, and not as a homogenised entity; as 'ours vs. theirs' and 'us vs. them' making a distinction between women agricultural laborers and women farmers. There is also an attempt to project an essentialized identity of dalit women whose material and subjective experiences tend to be different from the 'relatively' upper caste women in the village. The difference in experience within the same gender is largely attributed to permissibility about doing heavy work in one community, and not in the other. Broadly, all these vignettes suggest how caste and class can influence what kind of work is appropriate and what is not, even within the same gender. However, the different examples where different women in different 
circumstances operate the weeders, partially in some space and not others, suggests gender boundaries are not fixed but open to some degree of interpretation and contestation (Brandth, 1995; Pini, 2005).

\section{Technology, gender, accessibility issues, and the politics of (re) presentations}

The asset gap literature in agriculture have consistently raised the issue lack of access and ownership to assets which work much to the disadvantage of women farmers (Doss, 2001; Deere and Doss, 2006). Theoretically, in the case of the weeder; access and availability should not be an issue, exactly for the same reasons which SRI advocates tend to raise, which is its cost-effectiveness and simplicity in design. In addition, it is a one-time purchase, with little or no maintenance requirement, but that is exactly what is happening. Perhaps it is the mechanism(s) by which this equipment is made available to farmers. As mentioned earlier, it is through a government distributed scheme, where weeders are distributed to a prepared list of beneficiaries based on a well-defined guideline which is supposedly inclusive, representative of all farmer categories. But as is the case with most government schemes how that list is prepared and benefits accrued has its own politics and dynamics (e.g. elite capture). Though some pro-active local, non-government organizations (NGOs) like PRAN in order to address this shortfall issue have attempted to create a kind of 'community bank' with the local village resource person (VRP) to whom six to ten weeders are allocated for free hire and use. This initiative is helpful, but only up to a certain extent. The crux of this whole situation is, that such limited sources for access has a bearing on who, or how many households in the village has or can have access to the weeders.

There are obvious questions as to what restricts the local production and supply of a technology that has so little cost barrier? Demand, certainly at the time of research was an issue, as SRI as a new rice cultivation technique at the time of fieldwork was still in its initial phase of promotion and practice. There were also issues about lack of incentivization that could encourage local fabrication and supply, which is critical for any new technology introduction (Clarke, 2000). Some might want to argue that if SRI is not practiced in most plots of land in the studied sites, then obviously not much labor is being displaced in the process. One can have a sense of the scale of the potential displacement if the issue is viewed from a macro-level. The state of Bihar aims to encourage SRI adoption on onetenth (0.3 million ha) of the total area (3.6 million ha) under rice cultivation in Bihar. I 
reckon, lack of weeder availability can not only have a bearing on SRI adoption, but also how much yield is accrued eventually, considering there is a direct co-relation between weeding and yield.

The socio-cultural aspect around gender and technology as discussed above is certainly one of the reasons limiting use. However, what I also argue here is the selective deployment of the socio-cultural dimension of the argument as far as the weeder is concerned. The reason why I say so is because some women farmers (even from the OBC community) on request from the local NGO/government staff, comfortably exbibit their ability to operate the weeders in the presence of any senior government representative or to any outside visitors/researchers like me. I suggest that one has to make a distinction between the ability to versus expected to operate the technology in question. Socio-cultural norms as a reason limiting use isn't a fair argument, as there are many different ways SRI as a technique has created space(s) for women farmer's mobility and visibility not just at the district, but regional and national level where they have travelled to share their experiences of SRI cultivation. This, at times have entailed ignoring the social mores of the society. Why then on the question of gender and technology it is difficult to think of such transformative possibilities? The local government agency, the Agricultural Technology Management Agency (ATMA) organized many trainings for women agricultural laborers (e.g. ropanbaar training) in different blocks of Bodhgaya with the idea that such trained workers can act as a skilled pool of SRI paddy transplanters. No such trainings on the operation of the weeder technology were organized for women farmers at the time of research-potentially missing the opportunity to change the narratives around this technology. What is perplexing however is, how images of women in most government and non-government organization's posters, pamphlets, websites, annual reports and training manuals in Bihar are used to project women as using the weeder. It is without doubt that some of these organizations are sincerely committed to the idea of low-cost and environment-friendly techniques like SRI for rural development. The trouble however is, when such projections of positive imagery on certain aspects of the technology and practice belie the ground reality.

\section{Conclusion}

This paper demonstrates that just by the mere fact that a technology is gender-friendly, does not necessarily mean that women farmers will automatically benefit from it. It shows 
how for different reasons (access and availability issues of the weeders, social norms around gender, caste and class and preference/and or expectations from men around technology instead of women) all mediate in a mutually reinforcing way; thus, shaping and influencing material consequences which are different for different categories of farmers and farm workers. For instance, for small and marginal farmers practicing SRI, contribution from the men folks of the household in a role and space (essentially seen as feminine) has certainly provided some relief to such women farmers. Apart from that, the weeder technology has weakened the traditional gender-based 'task specificity' suggesting social norms are not fixed, they are mutable and evolve over time. But as discussed, with the slightest opportunity, that role and space can be outsourced to other men from the laboring community, bypassing women agricultural laborers from the same community who could potentially continue their existing role using the weeder.

As a larger point, if small-scale farming have to play a key role in food security/ food sovereignty debates and if the question is between expanding women's technological abilities and opportunities, versus men transcending their gender roles to 'pitch in' and contribute, (which is weeding with the weeder in this case); then the former should take precedence over the latter. No matter how promising any agricultural technique is, achieving enhanced farm productivity, efficiency or even drudgery reduction at the cost of the declining economic stake of women from agriculture, cannot be a long-term, feasible option $^{8}$. Policy and practice has evidently progressed from being 'gender-blind' to 'genderaware' as far as technology is concerned. But for change to occur, policy-makers and practitioners together have a key role in creating space(s) for women farmers which are not just inclusive, but rather transformative. Would more weeder accessibility and availability than now help alter the gender dynamics of the situation? Possibly yes. 


\section{References}

Adusumilli, R., Laxmi, S.B.(2011). Potential of the system of rice intensification for systemic improvement in rice production and water use: the case of Andhra Pradesh, India. Paddy Water Environment, 9, 89-97.

Agarwal, B.(1984). Rural women and high yielding variety rice technology. Economic and Political Weekly, A39-A52.

Barah, B.(2009). Economic and ecological benefits of system of rice intensification (SRI) in Tamil Nadu. Agricultural Economics Research Review, Vol. 22, 209-214.

Barrett, C.B., Moser, C.M., McHugh, O.V. and Barison, J.(2004). Better technology, better plots, or better farmers? Identifying changes in productivity and risk among Malagasy rice farmers. American Journal of Agricultural Economics, 86(4), pp.869-888.

Billings, M.H., Singh, A.(1970). Mechanisation and the wheat revolution: effects on female labour in Punjab. Economic and Political Weekly, 5, A169-A174.

Bordo, S.(1993). Unbearable weight: feminism, western culture, and the body. University of California Press, Berkley; Los Angeles; London.

Boserup, E.(1991). Agricultural growth and population change. In the World of Economics (pp. 1-14). Palgrave Macmillan UK.

Boyer, Kate, und Kim England. (2008).Gender, work and technology in the information workplace: from typewriters to ATMs“. Social \& Cultural Geography, 9, 3 (2008): 241256.

Brandth, B.(1995). Rural masculinity in transition: gender images in tractor advertisements. Journal of Rural Studies, 11, 123-133.

Brandth, B., (2006). Agricultural bodybuilding: incorporations of gender, body, and work. Journal of Rural Studies, 22, 17-27.

Carr,M. and Hartl, M.(2010). Lightening the load: labour-saving technologies and practices for rural women. IFAD, Rome.

Chakravarti, U.(1995). Gender, caste and labour: ideological and material structure of widowhood. Economic and Political Weekly, 30, 2248-2256.

Clarke, L.J.(2000). Strategies for Agricultural Mechanization Development: The Roles of the Private Sector and the Government.

Cockburn, C. and Ormrod, S.(1993). Gender and technology in the making. SAGE Publications Ltd, London.

Deshmukh, G., and Tiwari, R.K.(2011). Impact of weeders for weed management in system of rice intensification (SRI). Indian Journal of Weed Science, Volume: 43, 243244.

Doss, C.R.(2001). Designing agricultural technology for African women farmers: Lessons from 25 years of experience. World Development; 29, 2075-2092

Deere, C.D. and Doss, C.R.(2006). The gender asset gap: What do we know and why does it matter? Feminist Economics, 12(1-2), pp.1-50.

Elmhirst, R. and Resurreccion, B.P.(2008). Gender, environment and natural resource management: New dimensions, new debates. Gender and natural resource management: Livelihoods, mobility and interventions, pp.3-22.

Evans, A.(1991). Gender issues in rural household economics. IDS Bulletin, 22(1), pp.5159.

FAO 2011. Save and grow. A policymaker's guide to the sustainable intensification of smallholder crop production. Rome, Italy.

Faulkner, W. (2001). The technology question in feminism: A view from feminist technology studies“. In Women's Studies International Forum, 24:79-95. 
Gathorne-Hardy, A., Reddy, D.N., Venkatanarayana, M. and Harriss-White, B., 2016. System of Rice Intensification provides environmental and economic gains but at the expense of social sustainability-A multidisciplinary analysis in India. Agricultural Systems, 143, pp.159-168.

Ghritlahre, S.K., Sarial, A.K., Ram, M., Aneja, D.R., Singh, R.(2012). Genetic yield potential of rice (Oryza Sativa) through water saving and high-yielding SRI technology. Indian Journal of Agricultural Science, 82.

Grint, K. and Gill, R.(1995). The gender-technology relation: contemporary theory and research. Taylor \& Francis. London.

Grint, K. and Woolgar, S. (1995).On some failures of nerve in constructivist and feminist analyses of technology“. Science, Technology \& Human Values, 20, Nr. 3 (1995): 286310.

Harriss-White, B.(2005). Commercialisation, commodification and gender relations in post-harvest systems for rice in South Asia. Economic and Political Weekly,Vol. 40, Issue No. 25.

Hart, G.(1991). Engendering everyday resistance: gender, patronage, and production politics in rural Malaysia. Journal of Peasant Studies, 19, 93-121.

Heyer, J.(2000). The Changing position of agricultural labourers in villages in rural Coimbatore, Tamil Nadu, between 1981/2 and 1996. Queen Elizabeth House,Oxford Working Paper Series 27.

HLPE, (2013). Investing in smallholder agriculture for food security. A report by the high level panel of experts on food security and nutrition of the committee on World Food Security, FAO, Rome. Italy.

IFAD, (2013). Smallholder, food security and the environment. Rome. Italy.

Jackson, C.(1998). Gender, irrigation, and environment: arguing for agency. Agriculture and Human Values, 15, 313-324.

Kassam, A., Stoop, W., Uphoff, N.(2011). Review of SRI modifications in rice crop and water management and research issues for making further improvements in agricultural and water productivity. Paddy and W ater Environment, 9, 163-180.

Kishtwaria, J., and Rana, A.(2012). Ergonomic interventions in weeding operations for drudgery reduction of hill farm women of India. Work,41, 4349-4355.

Kolli, R.D and Bantilan, C. (1997). Gender-related impacts of improved agricultural technologies: Identification of indicators from a case study. Gender, Technology and Development, 1(3), pp.371-393

Liepins, R.(2000). Making men: The construction and representation of agriculture-based masculinities in Australia and New Zealand. Rural sociology, 65(4), pp.605-620.

Lohan, M. and Faulkner, W.(2004). Masculinities and technologies: some introductory remarks. Men and Masculinities, 6, 319-329.

MacKenzie, D. and Wajcman, J. (1999).The social shaping of technology. Open University Press.

Mehta, M., Gandhi, S., Dilbaghi, M.(2012). Intervention of drudgery reducing technologies in agriculture and impact evaluation. Work, 41, 5003-5008.

Mohanty D K, Mohanty M K(2010). Assessment of yield using cono-weeder in SRI method of paddy cultivation. Agricultural Engineering Today, Volume: 34, 21-24.

Mrunalini, A. and Ganesh, M.(2008). Workload on women using cono-weeder in SRI method of paddy cultivation. ORYZA- An International Journal on Rice, Volume: 45, 58-61.

Nightingale, A.J. (2011). Bounding difference: intersectionality and the material production of gender, caste, class and environment in Nepal. Geoforum, Themed Issue: New Feminist Political Ecologies 42, 153-162.

Nussbaum, M.C. (1995). Objectification. Philosophy \& Public Affairs 24, 249-291. 
Omvedt, G.(1979). The downtrodden among the downtrodden: An interview with a Dalit agricultural laborer. Signs, 4(4), pp.763-774.

Paris, T. andPingali, P. (1994). 'Do agricultural technologies hurt or help poor farm women?' enhancing incomes of rural women through suitable engineered systems, IRRI Discussion Paper Series 4-13.

Pini, B.(2005). Farm women: driving tractors and negotiating gender. International Journal of Sociology of Agriculture and Food, 13(1), pp.1-18.

Rao, N. and Rana, K.(1997). Women's labour and migration: the case of the Santhals. Economic and Political Weekly; 32, 3187-3189.

Sabarmatee, T.(2014). System of rice intensification (SRI) and laboring bodies: Exploring socio-technical interactions. January 15 . Wageningen University.

Satyanarayana, A.,Thiyagarajan, T.M., Uphoff, N.(2007). Opportunities for water saving with higher yield from the system of rice intensification. Irrigation Science, 25, 99-115.

Saugeres, L.(2002). "She's not really a woman, she's half a man": gendered discourses of embodiment in a French farming community. Women's Studies International Forum, 25, 641-650.

Singh, S.P., Gite, L. and P.J., Agarwal, N.(2006). Improved farm tools and equipment for women workers for increased productivity and reduced drudgery. Gender Technology and Development 10, 229-244.

Uphoff, N.(2003). Higher yields with fewer external inputs? The system of rice intensification and potential contributions to agricultural sustainability. International Journal of Agricultural Sustainability, 1, 38-50.

Uphoff, N., Randriamiharisoa, R.(2002). Reducing water use in irrigated rice production with the Madagascar system of rice intensification (SRI). Water-Wise Rice Production. IRRI, Los Baños, Philippiness 71-87.

Wajcman, J. (1991).Feminism confronts technology. Penn State Press.

Wajcman, J.(2010). Feminist theories of technology. Cambridge Journal of Economics, 34(1), pp.143-152. 


\section{Notes}

1 Conventional agriculture methods referred to here is the standardized, Green Revolution models of farming

2 Dalits are at the bottom of the Hindu caste system, and formerly known as the 'untouchables' castes. They constitute as one of the most marginalized communities in socio-economic and political terms.

3 Mahadalit is a sub-group within the dalits and constitutes the poorest and most marginalized within this group.

4 At the time of research, the only mechanism the weeder was available to the farmers was through asubsidized distribution of 'SRI Kit' during an annual government organized event of Kharif Mahotsav, in which the weeder is one of the many items in the kit.

5 National Bank for Agriculture and Rural Development (NABARD) is an apex development bank in India

${ }^{6}$ Also see studies on opportunity cost of men's labor time in the market and gendered difference in intrahousehold time allocation (e.g. Evans, 1991)

7 The period between sowing and harvesting of paddy, is the lean period especially for the poor, where income opportunities are few; and experiences of disease, illness, and poverty are the highest. It is a tradeoff therefore, between having the opportunity to work somewhere even if stressful, to no work. No work can mean no food in some households, as wages are paid in kind (mostly rice).

8 This is important within the context of 'feminization of agriculture' in much of the global South. 